\title{
Clinical and quantitative computed tomography predictors of response to endobronchial lung volume reduction therapy using coils
}

This article was published in the following Dove Press journal: International Journal of COPD

\author{
Konstantina Kontogianni ${ }^{1,2}$ \\ Kanoe Russell ${ }^{3}$ \\ Ralf Eberhardt ${ }^{1,2}$ \\ Maren Schuhmann ${ }^{1,2}$ \\ Claus Peter Heussel ${ }^{2,4}$ \\ Susan Wood ${ }^{3}$ \\ Felix JF Herth ${ }^{1,2}$ \\ Daniela Gompelmann ${ }^{1,2}$ \\ 'Department of Pulmonology \\ and Respiratory Care Medicine, \\ Thoraxklinik at the University of \\ Heidelberg, Heidelberg, Germany; \\ ${ }^{2}$ Translational Lung Research \\ Center Heidelberg, Member of the \\ German Center for Lung Research \\ DZL, Heidelberg, Germany; ${ }^{3}$ VIDA \\ Diagnostics, Coralville, IA, USA; \\ ${ }^{4}$ Diagnostic and Interventional \\ Radiology with Nuclear Medicine, \\ Chest Clinic (Thoraxklinik), \\ University of Heidelberg, Heidelberg, \\ Germany
}

Objectives: Bronchoscopic lung volume reduction using coils (LVRC) is a well-known treatment option for severe emphysema. The purpose of this study was to identify quantitative computed tomography (QCT) and clinical parameters associated with positive treatment outcome.

Patients and methods: The CT scans, pulmonary function tests (PFT), and 6-minute walk test (6-MWT) data were collected from 72 patients with advanced emphysema prior to and at 3 months after LVRC treatment. The procedure involved placing 10 coils unilaterally. Various QCT parameters were derived using Apollo imaging software (VIDA). Independent predictors of clinically relevant outcome ( $\Delta 6-\mathrm{MWT} \geq 26 \mathrm{~m}, \Delta \mathrm{FEV}_{1} \geq 12 \%, \Delta \mathrm{RV} \geq 10 \%$ ) were identified through stepwise linear regression analysis.

Results: The response outcome for $\Delta 6-\mathrm{MWT}$, for $\Delta \mathrm{FEV}_{1}$ and for $\Delta \mathrm{RV}$ was met by $55 \%, 32 \%$ and $42 \%$, respectively. For $\Delta 6$-MWT $\geq 26 \mathrm{~m}$ a lower baseline 6-MWT ( $p=0.0003)$ and a larger standard deviation (SD) of low attenuation cluster (LAC) sizes in peripheral regions of treated lung ( $p=0.0037$ ) were significantly associated with positive outcome. For $\Delta \mathrm{FEV}_{1} \geq 12 \%$, lower baseline $\mathrm{FEV}_{1}(p=0.02)$ and larger median LAC sizes in the central regions of treated lobe ( $p=0.0018$ ) were significant predictors of good response. For $\Delta \mathrm{RV} \geq 10 \%$ a greater baseline TLC $(p=0.0014)$ and a larger SD of LAC sizes in peripheral regions of treated lung ( $p=0.007)$ tended to respond better.

Conclusion: Patients with lower FEV 1 and 6-MWT, with higher TLC and specific QCT characteristics responded more positively to LVRC treatment, suggesting a more targeted CT-based approach to patient selection could lead to greater efficacy in treatment response.

Keywords: COPD, emphysema, interventional pulmonology, bronchoscopy, endoscopic lung volume reduction, endobronchial coils

\section{Plain language summary}

Our aim was to investigate and recognize possible quantitative computed tomography and/or clinical parameters which might be associated with positive lung volume reduction outcomes after endobronchial coils implantation (LVRC) in patients with severe heterogeneous emphysema. Our results showed that such predictors do exist. Taking those predictors into account, a more targeted approach to patient selection could lead to greater efficacy in treatment response.

\section{Introduction}

Emphysema is often a key component of COPD and is characterized by irreversible lung tissue destruction and loss of elasticity. It leads to air trapping and hyperinflation causing progressively worsening dyspnea and exercise capacity, significantly impairing the patient's quality of life. ${ }^{1}$ 
In the past decade, different approaches for endoscopic lung volume reduction (ELVR) have been developed. These approaches differ in indication, mechanism of action, reversibility, and complications, and are divided into blocking and nonblocking techniques. ELVR by means of endobronchial valve placement has the most widespread clinical use to date. ${ }^{2-6}$ However, valve placement is only successful in patients with absent interlobar collateral ventilation. Bronchoscopic lung volume reduction using coils (PneumRx Inc., Mountain View, CA, USA), is a nonblocking approach for ELVR and thus independent of collateral ventilation. Since the first publication of coil implantation by Herth et al in $2010,{ }^{7}$ several trials have reported encouraging results regarding its effectiveness..$^{8-11}$

Patient selection for ELVR has been modeled on the National Emphysema Treatment Trial (NETT) ${ }^{11,12}$ while the optimal criteria currently used are summarized in an expert recommendation panel from the year $2017\left(\mathrm{FEV}_{1}<50 \%\right.$, $\mathrm{RV}<175 \%$, RV/TLC $<0.58$, 6-MWT 150-450 m). ${ }^{13}$ However, in order to identify optimal candidates for each ELVR approach and thus improve treatment outcome, dedicated screening is necessary. Until recently, little was known about the specific characteristics of subjects more likely to respond better to endoscopic lung volume reduction treatment using coils (LVRC). In the biggest randomized controlled trial (RCT) related to coil therapy, the RENEW trial, ${ }^{14}$ the residual volume and the emphysema distribution were found to be predictors for successful coil treatment. Although routine visual analysis of emphysema can be performed with a good degree of confidence using computed tomography (CT) images, experienced readers might be required for a more reliable assessment. To increase the consistency of the assessment, automated software solutions are available for quantifying emphysema destruction and distribution using quantitative CT (QCT).

Various QCT predictors of ELVR treatment outcome using valves have been evaluated so far. Low-attenuation area percentage (LAA\%), heterogeneity score and fissure integrity (FI) score ${ }^{15-17}$ appear to aid in the selection process of patients and lobe for valve placement. However, it is still unknown if QCT measures are also predictors of LVRC therapy. In our retrospective study, we sought to determine QCT and clinical predictors of LVRC outcome to objectively guide and improve the selection of subjects.

\section{Patients and methods}

\section{Patients and study design}

Seventy-two patients (male/female: 35/37, mean age: $63 \pm 6.7$ years) who underwent unilateral LVRC treatment at the Thoraxklinik at university of Heidelberg were analyzed retrospectively. This study was a single-center analysis of a patient cohort which was treated with LVRC outside of clinical trials. Patients with severe heterogeneous emphysema and bilateral incomplete interlobar fissures were included. The study protocol was approved by the ethics committee of the University of Heidelberg (ethics number S-609/2012). All patients gave consent for the scientific use of the data acquired during hospitalization. Furthermore, the majority of the patients were treated within different prospective trials for endoscopic lung volume reduction after additional written consent. As the data in this current analysis were retrospectively analyzed no further patient consent was required. All subjects were ex-smokers who quit smoking at least 4 months before coil placement. The patients were deemed suitable candidates for LVRC according to previously described inclusion and exclusion criteria for ELVR. ${ }^{2}$

The pulmonary function tests (PFTs) were performed using the Erich Jaeger MasterLab Plethysmograph, per current American Thoracic Society/European Respiratory Society guidelines, and for the static volumes the reference values ECCS93 were used. PFT, 6-minute walk test (6-MWT), dyspnea score, image data from multi detector CT (MDCT) scan, a perfusion scan and echocardiogram were performed prior to and 3 months following the coil therapy. ${ }^{18,19}$

A combination of rigid and flexible bronchoscopy under general anesthesia was performed as per hospital standard. A total of 10 coils were placed in a single lobe and in a single session under fluoroscopic guidance into the subsegmental bronchi of the lobe most affected by emphysema per MDCT evaluation (Figure 1). Details of the coil design,

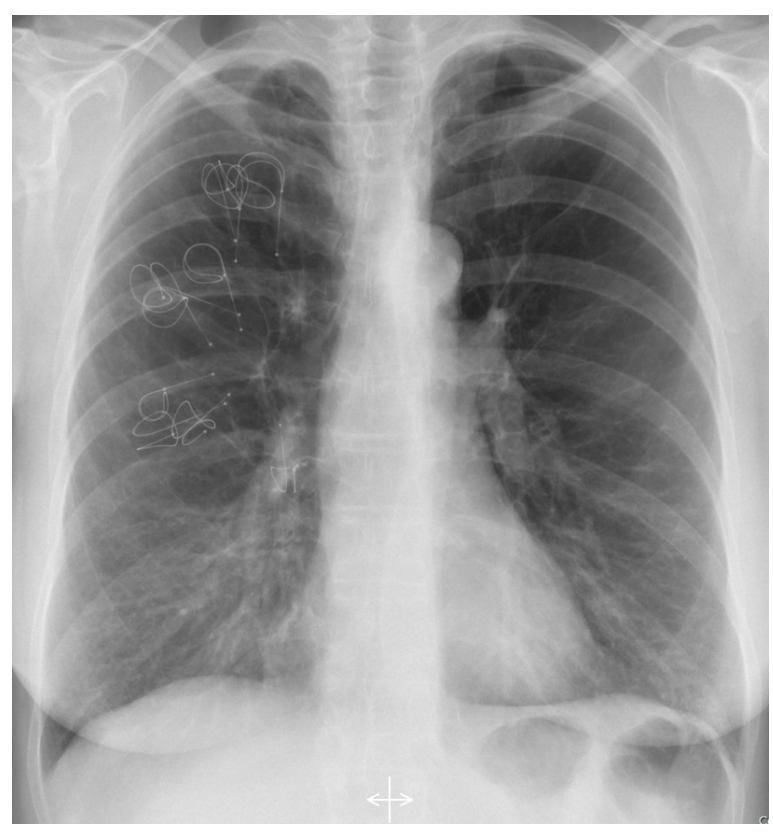

Figure I X-ray of a patient with coils in the right upper lobe. 
sizes, function, and insertion technique have been described previously. ${ }^{7}$ Patients received intravenous antibiotic prophylaxis and remained in hospital under observation for 3-4 days on average.

\section{Responder analysis}

A positive treatment outcome for lung volume reduction (LVR), was defined as LVR $\geq 350 \mathrm{~mL}$ (lobar volume difference greater than $350 \mathrm{~mL}$ between baseline and follow-up) as previously described. ${ }^{2,15} \mathrm{An}$ increase in $\mathrm{FEV}_{1}$ by greater than $12 \%\left(\Delta \mathrm{FEV}_{1} \geq 12 \%\right)$ and a decrease in $\mathrm{RV}$ by greater than $10 \%(\triangle \mathrm{RV} \geq 10 \%)$ were found in previous studies to indicate the minimal clinically important difference (MCID) ${ }^{8,20}$ Finally, an increase of $26 \mathrm{~m}$ or greater in the 6-MWT ( $\triangle 6$-MWT $\geq 26 \mathrm{~m}$ ) was found to signify MCID from previous studies. ${ }^{21,22}$

\section{MDCT image acquisition and analysis}

All MDCT scans were acquired at full inspiration and expiration at baseline and 90 days after treatment. Acquisition of the non-enhanced CT images was achieved using Siemens Somatom Definition AS 64 or Siemens Emotion 6 scanners (Siemens, Erlangen, Germany). Acquisition parameters for the scanners were set to: $k V p=[100-120]$, effective $\mathrm{mAs}=[51-151]$, pitch $=1.5$, reconstruction kernel $=\mathrm{I} 40 \mathrm{f}$, dose modulation $=\mathrm{ON}$, slice spacing $=0.7 \mathrm{~mm}$, and slice thickness $=1 \mathrm{~mm}$ during an inspiratory and expiratory breathhold, respectively.

CT images were evaluated using the Apollo 2.0 software package and the VIDA Diagnostics, Inc. clinical image analysis service that is ISO13485 certified for quality control (Coralville, Iowa, USA). Low attenuation areas (LAAs) of the lung below the threshold of -950 Hounsfield units (HU) were used to quantify the severity of emphysema. Emphysema percentage (EP) is the fraction of LAA found in each lobe. Heterogeneity score (HS) is the difference between EP of the treated lobe and its ipsilateral lobe. A value of $>15 \%$ points is deemed to be heterogeneous disease whereas a value of $\leq 15 \%$ points is homogeneous. Low attenuation cluster (LAC) that reflect the size of the "emphysematous holes" is calculated by plotting the number of LAA clusters against the size of the clusters and taking the slope. ${ }^{23}$ LAC by lobes and central vs peripheral were reported. ${ }^{15}$ The LAC slope as well as the median size and the SD of LAC sizes was evaluated. A steep slope indicates fewer "big clusters" or more small emphysematous holes, possibly indicating early disease or diffuse pan-lobular emphysema while the SD of LAC is a possible indicator of disease homogeneity with a higher SD indicating more distributed disease. Air trapping was measured as the percentage of low attenuation areas that fell below -856 (HU) on the expiratory CT image. Finally, peripheral pulmonary vessel volume was measured as the percentage of volume of the small vessels of the segmented patient vessel tree relative to the overall vessel tree volume.

\section{Statistical analysis}

Stepwise linear regression analysis was used to classify independent predictors of positive clinical outcome to LVRC treatment. QCT baseline measurements were first put through a correlation analysis with outcome measures to simplify the QCT model. This simplified QCT model, baseline PFT and baseline 6-MWT, were run through a multiple regression analysis to find the various predictors of clinical relevant outcome (response criteria $\Delta 6$-MWT $\geq 26 \mathrm{~m}, \Delta \mathrm{FEV}_{1} \geq 12 \%$, and $\Delta \mathrm{RV} \geq 10 \%$ ).

\section{Results}

Baseline characteristics of the patients are shown in Table 1. Some $55 \%$ of our procedures involved the right upper lobe, $15 \%$ the left upper lobe, another $15 \%$ the left lower lobe and finally $13 \%$ involved the right lower lobe. No coils were placed in the right middle lobe and all patients were treated unilaterally. No periprocedural technical problems occurred.

At 3 months after LVRC, 51 out of the 72 subjects (71\%) met at least one PFT/6-MWT response criterion (Figure 2). The response outcome, $\Delta 6$-MWT $\geq 26 \mathrm{~m}$, was met the most frequently in $55 \%(34 / 62)$ of the patients. The response rate for $\Delta \mathrm{FEV}_{1} \geq 12 \%$ was $32 \%(26 / 70)$ while the response rate for $\Delta R V \geq 10 \%$ was $42 \%(29 / 69)$. A lobar volume reduction (LVR) $\geq 350 \mathrm{~mL}$ was met in $19 \%(14 / 72)$ of cases. Because of the poor response rate of LVR $\geq 350 \mathrm{~mL}$, it was not included in the stepwise linear regression analysis. Furthermore, $16 \%$ of the patients met the 6-MWT as well as the RV response criterion and $10 \%$ of the patients met both the 6-MWT and $\mathrm{FEV}_{1}$ or the $\mathrm{FEV}_{1}$ and $\mathrm{RV}$ response criteria, respectively; $20 \%$ of the patients met all three aforementioned response criteria.

The stepwise linear regression analysis was applied to the response criteria $\Delta 6-\mathrm{MWT} \geq 26 \mathrm{~m}, \Delta \mathrm{FEV}_{1} \geq 12 \%$, and $\Delta \mathrm{RV} \geq 10 \%$ to find predictors for LVRC treatment. Each response criteria consisted of a PFT/6-MWT component as well as a QCT component; they were all found to be statistically significant $(p<0.05)$. The clinical predictors for $\Delta 6-\mathrm{MWT} \geq 26 \mathrm{~m}, \Delta \mathrm{FEV}_{1} \geq 12 \%$, and $\Delta \mathrm{RV} \geq 10 \%$ were 6-MWT at baseline ( $p=0.0003), \mathrm{FEV}_{1}$ at baseline $(p=0.02)$, and TLC at baseline $(p=0.0014)$ respectively 
Table I Baseline characteristics of all patients together as well as of the responder and non-responder groups separately (A), accompanied by the response rates at 90 -day follow-up (B)

\begin{tabular}{|c|c|c|c|c|c|c|c|c|c|c|}
\hline \multicolumn{11}{|l|}{$\mathbf{A}$} \\
\hline \multirow[t]{3}{*}{ Characteristics } & \multicolumn{10}{|l|}{ Baseline } \\
\hline & \multirow[t]{2}{*}{$\overline{\text { All }}$} & \multicolumn{3}{|l|}{ Responder } & \multicolumn{3}{|c|}{ Non-responder } & \multicolumn{3}{|c|}{$\begin{array}{l}\text { Significance of } \\
\text { difference }(p)\end{array}$} \\
\hline & & FEV & RV & 6-MWT & FEV & RV & 6-MWT & FEV & $\mathbf{R V}$ & 6-MWT \\
\hline Male/female & $35 / 37$ & & & & & & & & & \\
\hline Age, years & $63(7)$ & $63.65(6.6)$ & $65(6)$ & $64(7)$ & $63.55(6.96)$ & $62(7)$ & $62(7)$ & 0.95 & 0.11 & 0.28 \\
\hline \multicolumn{11}{|l|}{ Lung function } \\
\hline $\mathrm{FEV}_{1}$, Lt & $0.70(0.2 \mathrm{I})$ & $0.67(0.19)$ & $0.73(0.22)$ & $0.71(0.19)$ & $0.72(0.2 \mathrm{I})$ & $0.68(0.19)$ & $0.70(0.22)$ & 0.37 & 0.35 & 0.94 \\
\hline $\mathrm{FEV}_{1}$, \% pred & $27(8)$ & $27(8)$ & $27(6)$ & $27(8)$ & $28(7)$ & $27(8)$ & $28(6)$ & 0.63 & 0.97 & 0.73 \\
\hline FVC, Lt & $2.06(0.69)$ & $2.07(0.73)$ & $2.13(0.83)$ & $2.0(0.67)$ & $2.06(0.70)$ & $2.03(0.59)$ & $2.1(0.78)$ & 0.97 & 0.54 & 0.69 \\
\hline FVC, \% pred & $61(17)$ & $63(20)$ & $63(16)$ & $60(18)$ & $61(16)$ & $61(19)$ & $64(14)$ & 0.54 & 0.73 & 0.34 \\
\hline $\mathrm{RV}, \mathrm{Lt}$ & $5.98(1.49)$ & $6.10(1.59)$ & $6.50(1.47)$ & $6.06(1.44)$ & $6.04(1.24)$ & $5.75(1.21)$ & $5.93(1.26)$ & 0.87 & 0.02 & 0.69 \\
\hline RV, \% pred & $277(57)$ & $280(53)$ & $288(49)$ & $275(45)$ & $280(47)$ & 275 (59) & $284(55)$ & 0.97 & 0.29 & 0.51 \\
\hline TLC, Lt & $8.10(1.79)$ & $8.18(1.64)$ & $8.66(1.73)$ & $8.11(1.54)$ & $8.22(1.70)$ & $7.79(1.43)$ & $8.07(1.64)$ & 0.91 & 0.03 & 0.91 \\
\hline RV/TLC, ratio & $73(10)$ & $74(9)$ & $75(8)$ & $74(8)$ & $75(6)$ & $74(7)$ & $74(7)$ & 0.75 & 0.41 & 0.62 \\
\hline \multicolumn{11}{|c|}{ Exercise capacity } \\
\hline 6-MWT, m & $239(93)$ & $224(105)$ & $235(113)$ & $216(92)$ & $251(85)$ & $247(78)$ & $280(84)$ & 0.25 & 0.62 & 0.006 \\
\hline
\end{tabular}

B

$\Delta$ (90-day follow-up - Baseline)

\begin{tabular}{|c|c|c|c|c|c|c|c|}
\hline \multirow[t]{2}{*}{ Characteristics } & \multirow[t]{2}{*}{ All } & \multicolumn{3}{|l|}{ Responder } & \multicolumn{3}{|c|}{ Non-responder } \\
\hline & & $\triangle$ FEV $_{1}$ & $\Delta R \mathbf{R}$ & $\Delta 6-M W T$ & $\triangle$ FEV $_{1}$ & $\Delta \mathbf{R V}$ & $\Delta 6-M W T$ \\
\hline \multicolumn{8}{|l|}{ Male/female } \\
\hline Age, years & & - & - & - & - & - & - \\
\hline \multicolumn{8}{|l|}{ Lung function } \\
\hline $\mathrm{FEV}_{1}, \mathrm{Lt}$ & $0.76(0.22)^{*}$ & $0.17(0.10)^{*}$ & $0.10(0.14)^{*}$ & $0.08(0.12)^{*}$ & $-0.02(0.08)$ & $0.02(0.11)$ & $0.03(0.13)$ \\
\hline $\mathrm{FEV}_{1}$, \% pred & $29(8)^{*}$ & $7(4)^{*}$ & $4(5)^{*}$ & $3(4)^{*}$ & $-I(4)$ & I (5) & I (5) \\
\hline FVC, Lt & $2.34(0.76)^{*}$ & $0.41(0.43)^{*}$ & $0.56(0.38)^{*}$ & $0.34(0.49)^{*}$ & $0.17(0.46)^{*}$ & $0.02(0.37)$ & $0.13(0.37)$ \\
\hline FVC, \% pred & $69(17)^{*}$ & $13(12)^{*}$ & $16(9)^{*}$ & $9(13)^{*}$ & $5(14)^{*}$ & $\mathrm{I}(\mathrm{I3})$ & $5(\mathrm{II})^{*}$ \\
\hline $\mathrm{RV}, \mathrm{Lt}$ & $5.60(1.36)^{*}$ & $-0.77(0.95)^{*}$ & $-1.43(0.7 \mathrm{I})^{*}$ & $-0.69(0.83)^{*}$ & $-0.29(1.03)$ & $0.22(0.53)^{*}$ & $-0.18(1.01)$ \\
\hline RV, \% pred & $255(60)^{*}$ & $-31(47)^{*}$ & $-60(36)^{*}$ & $-29(39)^{*}$ & $-14(43)^{*}$ & $9(25)^{*}$ & $-9(46)$ \\
\hline TLC, Lt & $7.95(1.52)^{*}$ & $-0.34(0.75)^{*}$ & $-0.86(0.72)^{*}$ & $-0.34(0.64)^{*}$ & $-0.18(0.91)$ & $0.24 *(0.58)$ & $-0.06(0.8 I)$ \\
\hline RV/TLC, ratio & $70(9)^{*}$ & $-7(6)^{*}$ & $-10(4)^{*}$ & $-6(7)^{*}$ & $-3(7)^{*}$ & I (4) & $-2(6)$ \\
\hline \multicolumn{8}{|l|}{ Exercise capacity } \\
\hline 6-MWT, m & $273(84)^{*}$ & $4 \mathrm{I}(53)^{*}$ & $45(57)^{*}$ & $67(37)^{*}$ & $22(55)^{*}$ & $18(50)^{*}$ & $-16(30)^{*}$ \\
\hline
\end{tabular}

Note: Data are presented as mean $( \pm S D) . * p<0.05$.

Abbreviations: FEV , forced expiratory volume in I second; RV, residual volume; TLC, total lung capacity; FVC, forced vital capacity; TLC, total lung capacity; 6-MWT, 6-minute walking test; mMRC score, modified Medical Research Council score; Lt, liters; m, meters.

(Table 2; Figure 3). Thereby, the lower the 6-MWT at baseline, the greater the 6-MWT increase achieved; the lower the $\mathrm{FEV}_{1}$ at baseline, the greater the $\mathrm{FEV}_{1}$ improvement achieved; the higher the TLC at baseline, the greater the RV reduction achieved.

The standard deviation of LAC sizes in the peripheral region of the treated lung was deemed a QCT predictor for $\Delta 6$-MWT $\geq 26 \mathrm{~m}(p=0.037)$, whereby larger SD of LAC sizes in peripheral regions of treated lung responded more frequently. A QCT predictor for $\triangle \mathrm{FEV}_{1} \geq 12 \%$ was the median size of LAC in the central region of the target lobe ( $p$ $=0.0018$ ), whereby larger median LAC sizes responded better to treatment. Lastly, the standard deviation of LAC size in the peripheral region of the target lobe $(p=0.007)$ was tested as a QCT predictor for RV reduction (Table 2; Figure 3). The larger the SD of LAC sizes in peripheral regions of the treated lung, the greater the RV reduction achieved. Other QCT parameters such as the EP, HS, and air trapping were found to not be predictors for positive outcome to LVRC treatment.

\section{Discussion}

We have observed variability in the clinical outcome amongst patients undergoing LVRC treatment in our hospital. Subject selection has previously relied on ad hoc criteria adapted from the NETT study. ${ }^{11}$ In this retrospective analysis, we assessed QCT measurements and possible clinical predictors of outcome with the aim of identifying optimal candidates and improving the treatment outcome. 


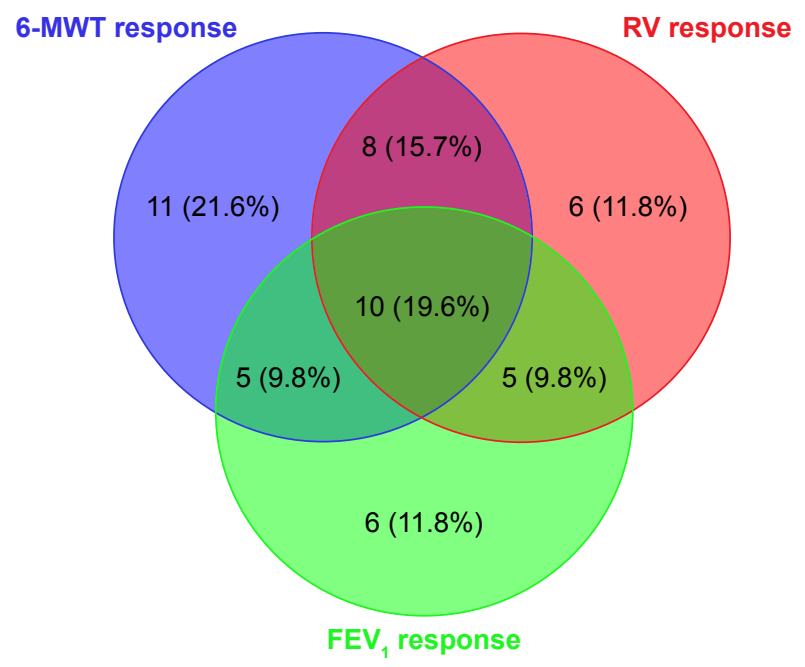

Figure 2 Treatment response rates for $\Delta 6-\mathrm{MWT} \geq 26 \mathrm{~m}, \Delta \mathrm{FEV}, \geq 12 \%$, and $\Delta R V \geq 10 \%$.

Abbreviations: $\mathrm{FEV}_{1}$, forced expiratory volume in I second; RV, residual volume; 6-MWT, 6-minute walking test.

Several single arm trials and three RCT evaluated the feasibility and efficacy of the LVRC treatment as minimally invasive therapeutic approach for patients with severe emphysema. ${ }^{9,10,24-28}$ The largest RCT is the RENEW (Effect of Endobronchial Coils Treatment vs Usual Care in Patients with Severe Emphysema) Trial, in that 315 emphysema patients were randomly assigned to a coil treatment group and to a standard medical care group..$^{14}$ At 12 months, a statistically significant between-group difference in median change was achieved for the 6-MWT with $14.6 \mathrm{~m}(p=0.02)$, for FEV with $7 \%(p<0.001)$ and for SGRQ with -8.9 points $(p<$ $0.001)$ each favoring the coil group. Although these results showed a statistically significant improvement in the clinical outcome measures, the between-group difference was modest and of uncertain clinical importance. To date, there are only limited data related to outcome predictors following LVRC treatment ${ }^{14,24}$ but identifying these predictors are crucial given the complexity, expense, and irreversibility of the treatment.

In this trial, we evaluated clinical and QCT outcome measures as potential predictors for the clinical outcome following coil treatment (Figure 4). Several studies have already evaluated the possible relationships among QCT and spirometric measurements of COPD severity, ${ }^{29}$ DLCO measurements, visual assessment of emphysema ${ }^{30}$ and physiological indices, eg, body-mass index (BMI). ${ }^{31}$ Furthermore, when comparing computerized evaluation to visual assessment, QCT is known to be less operator-dependent than visual grading of the severity of emphysema. ${ }^{32,33} \mathrm{QCT}$ outcome predictors for good response to endoscopic valve therapy were previously reported, ${ }^{15}$ but so far, no QCT variables are known that predict the outcome following coil treatment.
Table 2 Clinical and quantitative CT predictors of positive outcome to coils treatment

\begin{tabular}{|c|c|c|c|}
\hline $\begin{array}{l}\text { Positive } \\
\text { outcome }\end{array}$ & Predictors & $p$-value & Adj $R^{2}$ \\
\hline$\Delta 6-M W T$ & $\begin{array}{l}\text { 6-MWT at baseline } \\
\text { Standard deviation of low attenuation } \\
\text { cluster sizes in the peripheral region of } \\
\text { treated lung }\end{array}$ & $\begin{array}{l}0.0003 \\
0.037\end{array}$ & 0.22 \\
\hline$\Delta \mathrm{FEV}_{1}$ & $\begin{array}{l}\mathrm{FEV} \text {, at baseline } \\
\text { Median size of low attenuation clusters } \\
\text { in central region of the target lobe }\end{array}$ & $\begin{array}{l}0.02 \\
0.0018\end{array}$ & 0.15 \\
\hline$\Delta \mathrm{RV}$ & $\begin{array}{l}\text { TLC at baseline } \\
\text { Standard deviation of low attenuation } \\
\text { cluster sizes in the peripheral region of } \\
\text { the target lobe }\end{array}$ & $\begin{array}{l}0.0014 \\
0.007\end{array}$ & 0.28 \\
\hline
\end{tabular}

Abbreviations: $\mathrm{FEV}$, forced expiratory volume in I second; RV, residual volume; TLC, total lung capacity; 6-MWT, 6-minute walking test.

We noticed that patients exhibiting specific baseline clinical and QCT characteristics responded more positively to LVRC treatment. Clinical parameters of lower 6-MWT, lower $\mathrm{FEV}_{1}$, and higher TLC at baseline displayed higher likelihood of response to LVRC at 3-month follow-up. This finding correlates with a previous study result that a lower initial performance in the 6-MWT may predict an improvement in exercise capacity. ${ }^{10}$ Similar results were shown for patients undergoing lung volume reduction surgery ${ }^{11}$ or endoscopic valve therapy. ${ }^{34}$ Furthermore, patients with a high baseline TLC exhibited superior treatment response. Surprisingly, $\mathrm{RV}$ was not found to be a statistically significant outcome predictor. However a high TLC is also an indicator for severe hyperinflation and the RENEW trial similarly reported that severe hyperinflation ( $R V>225 \%$ ) was also found to predict a superior outcome following LVRC treatment. ${ }^{14}$ It should be kept in mind though, that not only one parameter should be used in order to determine the clinical importance of the therapy, but rather a combination of various parameters (eg, $\mathrm{FEV}_{1}, \mathrm{RV}, 6-\mathrm{MWT}$ ) that reflect in total the clinical relevance of this treatment approach. In this study however, the number of the patients was too small to evaluate predictors for combined efficacy outcome parameters.

Our QCT analysis showed that the standard deviation of LAC sizes in the peripheral region of the treated lung and in the peripheral region of the target lobe were a QCT predictor for 6-MWT MCID and for RV MCID, respectively. Furthermore, the median size of LAC in the central region of the target lobe showed a predictive value for the $\mathrm{FEV}_{1}$ MCID. These findings could indicate the mechanism of action of the coils. It is already known, that the regional emphysema distribution is associated with pulmonary function. ${ }^{35}$ Thereby, the emphysema severity in the central region 

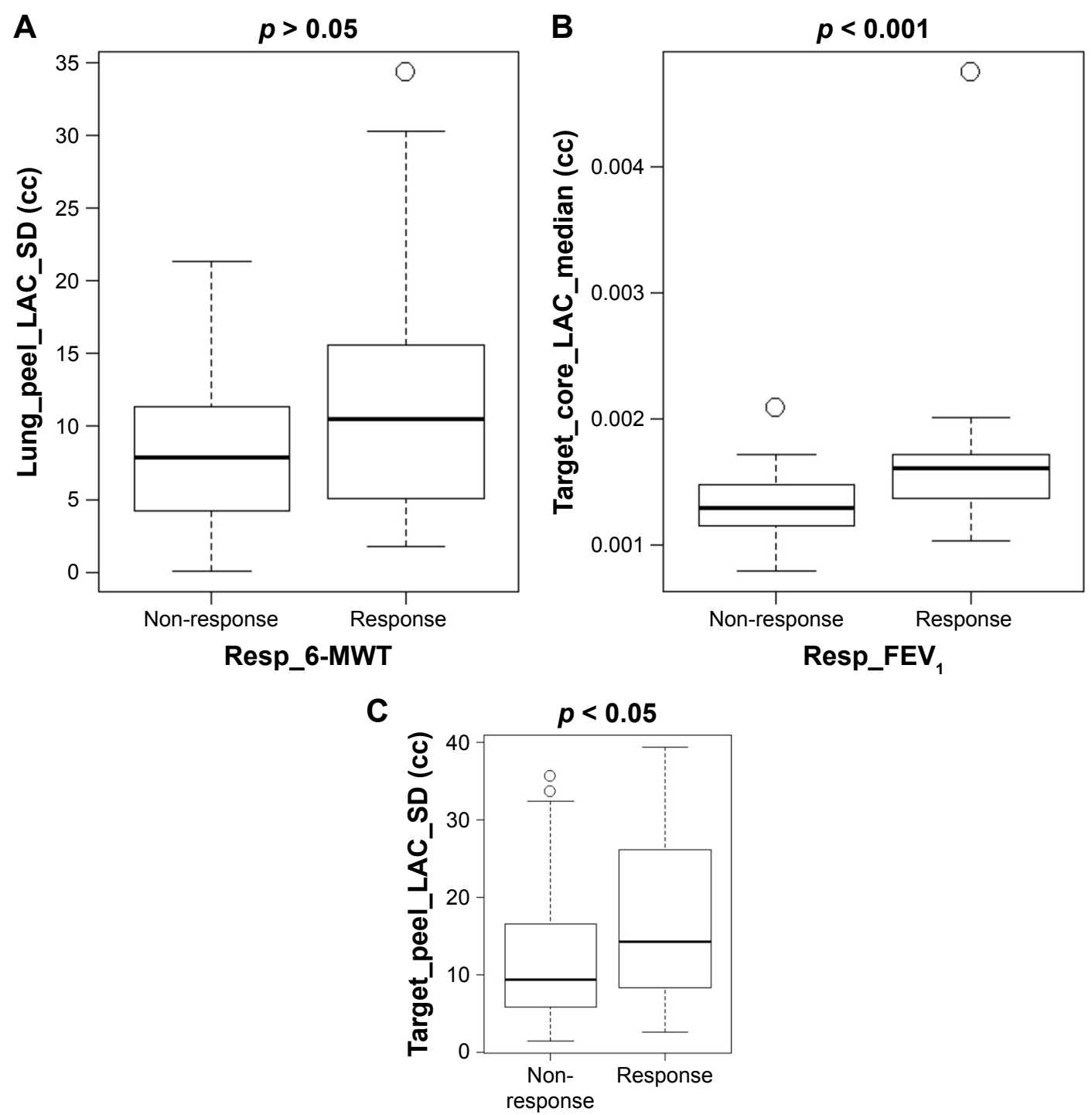

\section{Resp_RV}

Figure 3 (A) Box plot of responders to coils treatment looking at $\triangle 6-M W T>26 \mathrm{~m}$. Larger standard deviation of LAC sizes in peripheral regions of treated lung also responded more frequently. (B) Box plot of responders to coils treatment looking at $\triangle \mathrm{FEV}, \geq 12 \%$. Larger median LAC sizes in the central regions of treated lobe also responded more frequently. (C) Box plot of responders to coils treatment looking at $\triangle \mathrm{RV} \geq 10 \%$. Larger standard deviation of LAC sizes in peripheral regions of treated lobe also responded more frequently.

Abbreviations: $\mathrm{FEV}_{1}$, forced expiratory volume in I second; RV, residual volume; 6-MWT, 6-minute walking test; TLC, total lung capacity; LAC, low-attenuation cluster; Lt, liters; m, meters; cc, milliliters; SD, standard deviation.
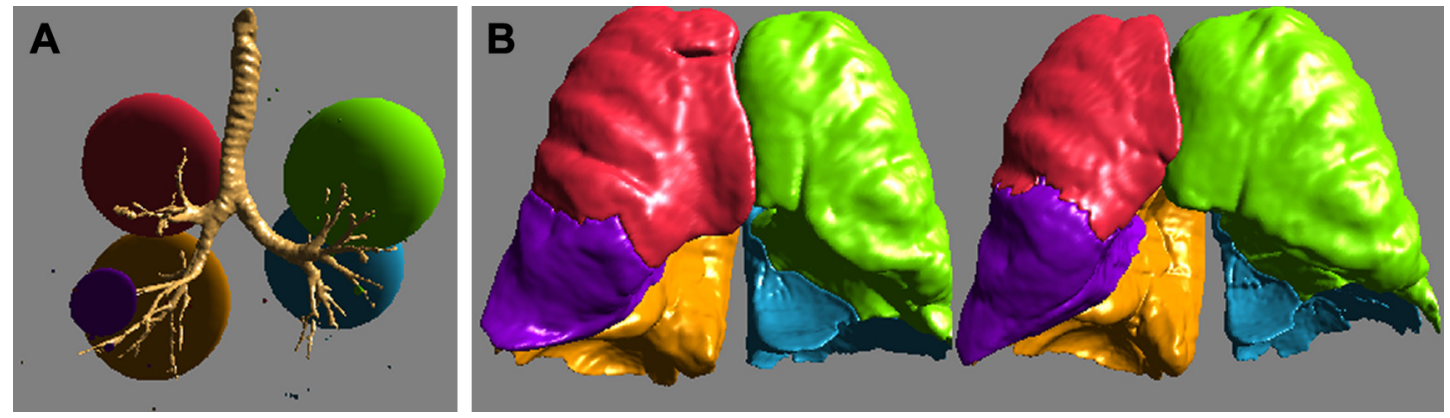

Figure 4 Lung volume reduction responder with severe emphysema treated for the right upper lobe, successfully identified as a responder by quantitative computed tomography. (A) Low-attenuation cluster representation of the patient at baseline. The low-attenuation area percentage of the right upper lobe (RUL) was found to be [LAA\%] - $950=40.41 \%$. (B) Three-dimensional surface lung volume reduction representation demonstrating a reduction in RUL volume of $531.3 \mathrm{~mL}$ after treatment, corresponding to a reduction by one-third of the baseline volume. Baseline (left) shows an enlarged RUL while post-treatment (right) shows the reduction of volume of RUL, and the relative expansion of the right middle lobe and the right lower lobe. 
of the lung affects the pulmonary function more than the peripheral emphysematous changes, potentially explaining why the median size of LAC of the central region influences the $\mathrm{FEV}_{1}$ in this trial (Figure 5). Peripheral disease seems to correlate better with static or dynamic hyperinflation and exercise capacity. Our findings suggest that a more inhomogeneous emphysema in the peripheral regions of the lung - which is reflected by a high standard deviation of LAC - responds better to coil treatment. However, HS on a lobar level was not found to be an outcome predictor. In this trial, we excluded patients with homogeneous emphysema. The pilot trial of LVRC in $2010^{7}$ showed that the efficacy favored patients with heterogeneous compared to homogeneous emphysema. Thus, the patients enrolled in our trial and treated between 2011 and 2015 had a heterogeneous emphysema distribution. The first trial that demonstrated the efficacy of coil therapy also in patients with homogeneous emphysema was published in 2014 by Klooster et al, ${ }^{26}$ while the first mention of efficacy of LVRC in a large cohort of patients with homogenous emphysema was in the recently published RENEW trial in 2016. ${ }^{14}$

A difficulty of identifying strong predictors of success has been previously demonstrated by Washko et al, in the outcome after lung volume reduction surgery in a large patient cohort of the NETT trial. The baseline burden of CT emphysema (LAA\% less than -950 Hounsfield units) and the

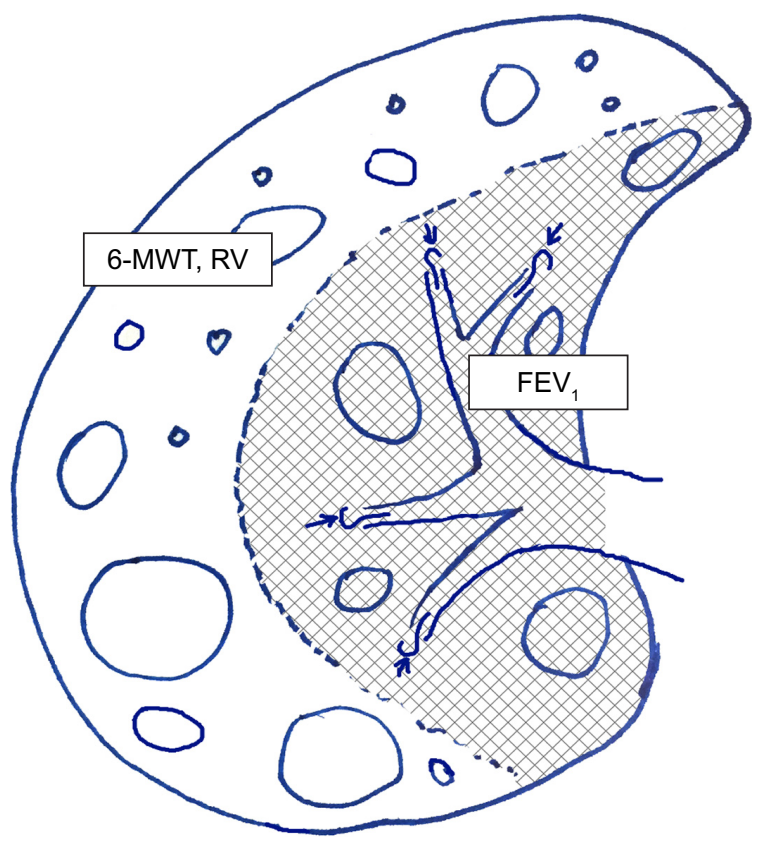

Figure 5 Importance of distribution of low attenuation clusters: central disease affects more the FEV, while the peripheral disease affects more the hyperinflation and the exercise capacity.

Abbreviations: $\mathrm{FEV}_{\text {, }}$, forced expiratory volume in I second; RV, residual volume; 6-MWT, 6-minute walking test. emphysema distribution (ratio upper to lower zone emphysema) were only weakly predictive of a subject's change in $\mathrm{FEV}_{1}$ and exercise capacity after surgical intervention. ${ }^{36}$ Our study is in concordance with these results, since we have not been able to find any correlation between EP, HS or air trapping with the outcome prediction.

\section{Limitations}

One significant limitation of this trial is that all patients were treated only unilaterally. Recently, it has been suggested that bilateral treatment is more efficacious. Therefore, the predictive factors should also be evaluated for the bilateral treatment approach. Another limitation is the retrospective character of the study. However, its aim was to identify predictors of success in patients treated with coils. Because radiological and lung-functional outcomes were unknown prior to treatment, a prospective analysis was not possible. Furthermore, the lack of a control group and the unblinded character of this study cannot exclude the possibility of introducing placebo effects in the PFT and exercise parameters, although QCT is mainly resistant to this influence. Another limitation is the post-treatment QCT parameters might also be affected by the presence of the numerous coils: they induce metallic hardening artifacts on CT as well as a different amount of increased density adjacent to the coils themselves potentially affecting the measurement and quantification of the emphysema parameters.

\section{Conclusion}

Patients exhibiting specific baseline clinical and QCT characteristics responded more positively to LVRC treatment. Patients with lower 6-MWT, FEV ${ }_{1}$, and higher TLC at baseline displayed a tendency to respond better. Patients with higher standard deviations in LAC size in the peripheral region of the treated lung or treated lobe had superior treatment outcome to 6-MWT and RV. Patients with higher median size of LAC size in the central regions of the treated lobe also experienced a more positive $\mathrm{FEV}_{1}$ outcome. These findings emphasize the role of accurate patient selection in successful coil therapy. In this study different parameters were found to be statistically significant, independent positive predictors of LVRC therapy outcome. However, for each patient all the aforementioned parameters should be evaluated to increase the likelihood of positive outcome. Additional studies are needed to improve the understanding of the predictive factors of response to better select the responders to LVRC and to prove the benefits and impact of this new QCT approach for adoption in routine clinical 
practice. Only with more precise patient selection will coil therapy become established as a substantial treatment for patients with advanced emphysema.

\section{Acknowledgment}

The authors acknowledge financial support by Deutsche Forschungsgemeinschaft within the funding programme Open Access Publishing, by the Baden-Württemberg Ministry of Science, Research and the Arts and by RuprechtKarls-Universität Heidelberg.

\section{Disclosure}

KK, KR and SW report no conflicts of interest in this work.

RE: Lecture and travel fees from Olympus, Pulmonx and Uptake Medical/Broncus outside the submitted work.

MS: Fees for lectures and advisory boards from the following companies: Olympus, Pulmonx, Astra Zeneca, Novartis, Teva, GSK, PneumRx and Boston Scientific outside the submitted work.

CH: Stock ownership in medical industry, Stada, GSK; Patents Method and Device for Representing the Microstructure of the Lungs. IPC8 Class: AA61B5055FI, PAN: 20080208038, Inventors: W Schreiber, U Wolf, AW Scholz, CP Heussel; personal fees from Schering-Plough, personal fees from Pfizer, personal fees from Basilea, personal fees from Boehringer Ingelheim, personal fees from Novartis, personal fees from Roche, personal fees from Astellas, personal fees from Gilead, personal fees from MSD, personal fees from Lilly, personal fees from Intermune, personal fees from Fresenius, personal fees from Olympus, personal fees from Siemens, personal fees from MeVis, personal fees from Essex, personal fees from AstraZeneca, personal fees from Bracco, personal fees from MEDA Pharma, personal fees from Intermune, personal fees from Chiesi, personal fees from Covidien, personal fees from Pierre Fabre, personal fees from Grifols, personal fees from Bayer, other from Stada, other from GSK, outside the submitted work.

FH: Fees for lectures and advisory boards from Astra, Allmirall, Berlin Chemie, Boehringer, Roche, GSK, Pulmonx, BTG, Olympus, PneumRx, Boston Scientific, Medupdate, Grifols, CSL Behring, Omniamed, Lilly, Novartis, Teva, Uptake and Vital Air, outside the submitted work.

DG: Personal fees from Olympus, personal fees from Pulmonx, personal fees from Chiesi, personal fees from Berlin Chemie, personal fees from Astra Zeneca, personal fees from Boehringer Ingelheim, personal fees from Novartis, personal fees from Mundipharma, personal fees from Grifols, outside the submitted work.

\section{References}

1. Vogelmeier CF, Criner GJ, Martinez FJ, et al. Global strategy for the diagnosis, management, and prevention of chronic obstructive lung disease 2017 report. GOLD executive summary. Am J Respir Crit Care Med. 2017;195(5):557-582.

2. Sciurba FC, Ernst A, Herth FJ, et al; VENT Study Research Group. A randomized study of endobronchial valves for advanced emphysema. N Engl J Med. 2010;363:1233-1244.

3. Toma TP, Hopkinson NS, Hillier J, et al. Bronchoscopic volume reduction with valve implants in patients with severe emphysema. Lancet. 2003;361:931-933.

4. Davey C, Zoumut Z, Jordan S, et al. Bronchoscopic lung volume reduction with endobronchial valves for patients with heterogeneous emphysema and intact interlobar fissures (the BelLieVeR-HIFi study): a randomised controlled trial. Lancet. 2015;386:1066-1073.

5. Klooster K, ten Hacken NH, Hartman JE, Kerstjens HA, van Rikxoort EM, Slebos DJ. Endobronchial valves for emphysema without interlobar collateral ventilation. $N$ Engl J Med. 2015;373:2325-2335.

6. Valipour A, Slebos DJ, Herth FJ, et al; IMPACT Study Team. Endobronchial Valve Therapy in Patients with Homogeneous Emphysema. Results from the IMPACT Study. Am J Respir Crit Care Med. 2016; 194:1073-1082.

7. Herth FJ, Eberhardt R, Gompelmann D, Slebos DJ, Ernst A. Bronchoscopic lung volume reduction with a dedicated coil: a clinical pilot study. Ther Adv Respir Dis. 2010;4:225-231.

8. Slebos DJ, Klooster K, Ernst A, Herth FJ, Kerstjens HA. Bronchoscopic lung volume reduction coil treatment of patients with severe heterogeneous emphysema. Chest. 2012;142:574-582.

9. Shah PL, Zoumot Z, Singh S, et al. Endobronchial coils for the treatment of severe emphysema with hyperinflation (RESET): a randomised controlled trial. Lancet Respir Med. 2013;1:233-240.

10. Kontogianni K, Gerovasili V, Gompelmann D, et al. Effectiveness of endobronchial coil treatment for lung volume reduction in patients with severe heterogeneous emphysema and bilateral incomplete fissures: a six-month follow-up. Respiration. 2014;88(1):52-60.

11. Fishman A, Martinez F, Naunheim K, et al; National Emphysema Treatment Trial Research Group. A randomized trial comparing lungvolume-reduction surgery with medical therapy for severe emphysema. N Engl J Med. 2003;348(21):2059-2073.

12. McKenna RJ Jr, Brenner M, Fischel RJ, et al. Patient selection criteria for lung volume reduction surgery. $J$ Thorac Cardiovasc Surg. 1997;114:957-964, discussion 964-967.

13. Herth FJF, Slebos DJ, Criner GJ, Shah PL. Endoscopic lung volume reduction: an expert panel recommendation - update 2017. Respiration. 2017;94(4):380-388.

14. Sciurba FC, Criner GJ, Strange C, et al; RENEW Study Research Group. Effect of endobronchial coils vs usual care on exercise tolerance in patients with severe emphysema: the RENEW randomized clinical trial. JAMA. 2016;315(20):2178-2189.

15. Schuhmann M, Raffy P, Yin Y, et al. Computed tomography predictors of response to endobronchial valve lung reduction treatment. Comparison with Chartis. Am J Respir Crit Care Med. 2015;191(7): 767-774.

16. Herth FJ, Noppen M, Valipour A, et al; International VENT Study Group. Efficacy predictors of lung volume reduction with Zephyr valves in a European cohort. Eur Respir J. 2012;39:1334-1342.

17. $\mathrm{Pu}$ J, Wang $\mathrm{Z}, \mathrm{Gu} \mathrm{S}$, et al. Pulmonary fissure integrity and collateral ventilation in COPD patients. PLoS One. 2014;9(5):e96631.

18. Miller MR, Hankinson J, Brusasco V, et al. ATS/ERS Task Force. Standardisation of spirometry. Eur Respir J. 2005;26(2):319-338.

19. Wanger J, Clausen JL, Coates A, et al. Standardisation of the measurement of lung volumes. Eur Respir J. 2005;26(3):511-522.

20. Donohue JF. Minimal clinically important differences in COPD lung function. COPD. 2005:111-124. 
21. Puhan MA, Chandra D, Mosenifar Z, et al; National Emphysema Treatment Trial (NETT) Research Group. The minimal important difference of exercise tests in severe COPD. Eur Respir J. 2011;37(4): 784-790.

22. Holland AE, Hill CJ, Rasekaba T, Lee A, Naughton MT, McDonald CF. Updating the minimal important difference for six-minute walk distance in patients with chronic obstructive pulmonary disease. Arch Phys Med Rehabil. 2010;91(2):221-225.

23. Mishima M, Hirai $\mathrm{T}$, Itoh $\mathrm{H}$, et al. Complexity of terminal airspace geometry assessed by lung computed tomography in normal subjects and patients with chronic obstructive pulmonary disease. Proc Natl Acad Sci US A. 1999;96(16):8829-8834.

24. Deslee G, Klooster K, Hetzel M, et al. Lung volume reduction coil treatment for patients with severe emphysema: a European multicentre trial. Thorax. 2014;69(11):980-986.

25. Hartman JE, Klooster K, Gortzak K, ten Hacken NH, Slebos DJ. Longterm follow-up after bronchoscopic lung volume reduction treatment with coils in patients with severe emphysema. Respirology. 2015;20(2): 319-326.

26. Klooster K, Ten Hacken NH, Franz I, Kerstjens HA, van Rikxoort EM, Slebos DJ. Lung volume reduction coil treatment in chronic obstructive pulmonary disease patients with homogeneous emphysema: a prospective feasibility trial. Respiration. 2014;88(2):116-125.

27. Deslée G, Mal H, Dutau H, et al; REVOLENS Study Group. Lung volume reduction coil treatment vs usual care in patients with severe emphysema: the REVOLENS randomized clinical trial. JAMA. 2016; 315(2):175-184.

28. Kontogianni K, Gerovasili V, Gompelmann D, et al. Coil therapy for patients with severe emphysema and bilateral incomplete fissures effectiveness and complications after 1-year follow-up: a single-center experience. Int J Chron Obstruct Pulmon Dis. 2017;12:383-394.
29. Schroeder JD, McKenzie AS, Zach JA, et al. Relationships between airflow obstruction and quantitative CT measurements of emphysema, air trapping, and airways in subjects with and without chronic obstructive pulmonary disease. Am J Roentgenol. 2013;201(3):W460-W470.

30. Nambu A, Zach J, Schroeder J, et al. Relationships between diffusing capacity for carbon monoxide (DLCO), and quantitative computed tomography measurements and visual assessment for chronic obstructive pulmonary disease. Eur J Radiol. 2015;84(5):980-985.

31. Nambu A, Zach J, Schroeder J, et al. Quantitative computed tomography measurements to evaluate airway disease in chronic obstructive pulmonary disease: Relationship to physiological measurements, clinical index and visual assessment of airway disease. Eur J Radiol. 2016; 85(11):2144-2151.

32. Brown MS, Kim HJ, Abtin FG, et al. Emphysema lung lobe volume reduction: effects on the ipsilateral and contralateral lobes. Eur Radiol. 2012;22:1547-1555.

33. Gietema HA, Mueller NL, Fauerbach PVN, et al; Evaluation of COPD Longitudinally to Identify Predictive Surrogate Endpoints (ECLIPSE) investigators. Quantifying the extent of emphysema: factors associated with radiologists' estimations and quantitative indices of emphysema severity using the ECLIPSE cohort. Acad Radiol. 2011;18:661-671.

34. Gompelmann D, Hofbauer T, Gerovasili V, et al. Predictors of clinical outcome in emphysema patients with atelectasis following endoscopic valve therapy. Respirology. 2016;21:1255-1261.

35. Haraguchi M, Shimura S, Hida W, Shirato K. Pulmonary function and regional distribution of emphysema as determined by high-resolution computed tomography. Respiration. 1998;65(2):125-129.

36. Washko GR, Martinez FJ, Hoffman EA, et al; National Emphysema Treatment Trial Research Group. Physiological and computed tomographic predictors of outcome from lung volume reduction surgery. Am J Respir Crit Care Med. 2010;181:494-500.
International Journal of COPD

\section{Publish your work in this journal}

The International Journal of COPD is an international, peer-reviewed journal of therapeutics and pharmacology focusing on concise rapid reporting of clinical studies and reviews in COPD. Special focus is given to the pathophysiological processes underlying the disease, intervention programs, patient focused education, and self management protocols.

\section{Dovepress}

This journal is indexed on PubMed Central, MedLine and CAS. The manuscript management system is completely online and includes a very quick and fair peer-review system, which is all easy to use. Visit http://www.dovepress.com/testimonials.php to read real quotes from published authors. 